\title{
Medical profiteering: the economics of methadone dispensation
}

\author{
Bohdan Nosyk MA, Aslam H. Anis PhD
}

$\mathrm{O}$ n Sept. 9, 2008, reports in Canadian print and television media revealed that certain pharmacies in Vancouver's Downtown Eastside were paying patients up to $\$ 10$ a day to pick up methadone prescriptions at their pharmacy. A media outlet enlisted the help of a patient with a hidden camera to break the story, as Vancouver physicians prescribing methadone had long complained that their patients were being manipulated by some pharmacies. ${ }^{1}$

In a neighbourhood with a high density of people addicted to opioids, methadone dispensation has become highly competitive. A pharmacy may be viewed as a competitive firm whose objective is to maximize profits, and, in the case of methadone, the profit motive is particularly strong. In Canada, community pharmacies dispense methadone daily to those in treatment who ingest the drug under pharmacist supervision (daily witnessed ingestion).

Although the same product is dispensed everywhere, competition occurs in several ways. Some treatment providers differentiate their product by offering additional psychosocial care, most often in the context of a specialized treatment clinic, sometimes charging an additional monthly fee. Alternatively, some compete in terms of price by sharing with the patient the $\$ 16.60$ they receive in dispensing fees through the provincial government. Although the proximity of pharmacies increases competition, even a methadone-dispensing pharmacy with no natural competitors may find that offering monetary incentives increases its revenue.

This market-driven behaviour has both positive and negative consequences. On the positive side, the financial incentive to the client may improve retention in methadonetreatment programs. Voucher- or prize-based strategies, which are based on the same principle, have been tested with some success in methadone treatment programs in the United States. ${ }^{2}$

What is troublesome, however, is how the financial incentive is spent. An observational study found that untreated opioid-dependent patients can spend as much as $77 \%$ of their income on illicit drugs; ${ }^{3}$ much of this income is procured through drug-dealing and other forms of acquisitive crime.

Although methadone eliminates withdrawal symptoms and blocks the euphoric rush experienced with heroin, other illicit drugs can provide qualitatively different, yet comparably intense, chemical euphoria. Seminal studies of opioiddependent patients entering methadone maintenance treatment programs have suggested that $47 \%$ of patients also used cocaine. ${ }^{4}$ In a large prospective cohort study of injection drug users in Vancouver, crack cocaine use was independently associated with enrolment in a methadone maintenance program. ${ }^{5}$

Just as firms behave rationally to maximize profits, economic theory suggests that illicit drug users also behave rationally, albeit short-sightedly ${ }^{6}$ (i.e., they make consumption choices that maximize their current-value "utility" or well-

\section{Key points}

- Recent media reports have exposed pharmacists who are providing kickbacks to methadone customers.

- Price competition among methadone-dispensing pharmacies is a natural behaviour of profit-maximizing firms operating in a competitive market.

- The net effect of payments to methadone customers need not be negative because there is potential for improved adherence to treatment.

- Given the societal benefits resulting from increased access to treatment, policy changes that limit or decrease access to methadone maintenance treatment should be discouraged.

being). Although illicit drug use is harmful in the long run, consuming an illicit drug can bring about positive utility in the short term, in the form of euphoria and avoidance of withdrawal symptoms. One empirical study ${ }^{7}$ found high rates of time preference (a measure of how present-oriented an individual is in their decision-making) among active illicit drug users, suggesting that the long-term harms can be outweighed by the immediate benefit of drug consumption. Therefore, people dependent on multiple drugs who are unmotivated for treatment may adopt a strategy of managing their opioid withdrawal with methadone and effectively substituting the desired euphoric effects of heroin with crack cocaine. The income freed by eliminating the need to purchase illicit heroin can be used for crack or other illicit drugs. Therefore, financial incentives offered by pharmacies may add to the amount of income available for the purchase of illicit drugs and enhance the appeal of this strategy.

This is not to say that providing any form of economic transfer to people addicted to opioids is necessarily negative. The first and best method for such transfers to any disadvantaged group is unrestricted cash payments, such as welfare payments. If the secondary goal is to encourage rehabilitative treatment, then, with all else being equal, tying transfers to the actual consumption of methadone is the preferred solution. However, if the money paid is being used to fund the purchase of illicit cocaine, then the net effect of this policy may be negative. The payments could result in more problem cocaine use and crime and would constitute an abuse of methadone maintenance treatment that, once publicly known, would undermine support for the treatment. Further study is, therefore, needed to determine the effect of pharmacy payments as they occur in real-life settings.

Regardless of the competitive behaviour of some pharma-

From the Centre for Health Evaluation and Outcome Sciences (Nosyk, Anis) and the School of Population and Public Health (Anis), University of British Columbia, Vancouver, BC 
cies, making methadone maintenance treatment as widely available as possible is socially beneficial. A methodologically rigorous simulation study found that an additional $\$ 1$ spent on increasing access to treatment yields $\$ 76$ in discounted lifetime benefits. ${ }^{8}$ Deregulation and increases in the number of physicians prescribing methadone have coincided with a $240 \%$ increase in the number of patients in treatment since 1996. Thus, economic incentives for community pharmacies to continue to dispense methadone must remain to ensure widespread access.

Alternative strategies for providing methadone maintenance treatment exist. Office-based treatment is provided in countries such as the United Kingdom and Switzerland. In the United States, methadone is allowed only in opioid treatment programs, which face capacity constraints, shorter hours of operation and high human resource demands, leading to higher marginal costs. If one accepts the assumption that the marginal cost of using physicians or opioid treatment programs to provide methadone under a daily witnessedingestion program are higher, then both consumer surplus (utility gain) and producer surplus (pharmacy profits), and thus social welfare, are maximized with a pharmacy-based daily witnessed-ingestion program.

Thus, we recommend continuing the current pharmacybased model. Any policy changes that limit or decrease access to methadone maintenance treatment should be discouraged. Recognition of the economic incentives of all parties involved is imperative in understanding the illicit drug use phenomenon and devising effective strategies to reduce the social burden it imposes.

This article has been peer reviewed.

Competing interests: None declared.

Contributors: Both of the authors contributed to the conception of the article, revised it critically for important intellectual content and approved the final version submitted for publiction.

\section{REFERENCES}

1. Tomlinson K. Pharmacy paid addict kickback: hidden camera. CBCnews.ca; 2008. Available: www.cbc.ca/canada/british-columbia/story/2008/09/07/bc-prescription -for-profit.html?ref=rss\&loomia_si=t0:a16:g2:r1:c0.135526 (accessed 2009 Jan. 9).

2. Stitzer M, Petry N. Contingency management for treatment of substance abuse. Annu Rev Clin Psychol 2006;2:411-34.

3. Hutchinson SJ, Gore SM, Taylor A, et al. Extent and contributing factors of drug expenditure of injectors in Glasgow. Multi-site city-wide cross-sectional study. $\mathrm{Br}$ J Psychiatry 2000; 176:166-72.

4. Ball JC, Ross A. The effectiveness of methadone maintenance treatment. New York (NY): Springer-Verlag; 1991.

5. Kerr T, Marsh D, Li K, et al. Factors associated with methadone maintenance therapy use among a cohort of polysubstance using injection drug users in Vancouver. Drug Alcohol Depend 2005;80:329-35.

6. Becker GS, Murphy KM. A theory of rational addiction. J Polit Econ 1988;96: 675-700.

7. Bretteville-Jensen AL. Addiction and discounting. J Health Econ 1999;18:393-407.

8. Zarkin GA, Dunlap LJ, Hicks KA, et al. Benefits and costs of methadone treatment: results from a lifetime simulation model. Health Econ 2005;14:1133-50.

Correspondence to: Dr. Aslam H. Anis, 620B-1081 Burrard St., Vancouver BC V6Z 1Y6; fax 604 806-8778; aslam.anis@ubc.ca 